\title{
Barking up the wrong tree: por uma reflexão crítica da avaliação normativa
}

\section{Cristina Arcuri Eluf}

Professora Doutora da UNEB - Universidade do Estado da Bahia - Campus XIV Conceição do Coité; Conceição do Coité e do PPGCEL Programa de Pós-graduação em Letras: Cultura, Educação e Linguagens da UESB-Universidade Estadual do Sudoeste da Bahia; (orientadora); Vitória da Conquista, Bahia; Brasil criseluf@gmail.com

Resumo: $O$ estudo a seguir apresenta teorizações acerca da avaliação de língua inglesa, tendo como objeto de análise práticas avaliativas de uma escola pública do interior da Bahia. Ao perceber nesse contexto a regularidade de práticas conservadoras, pautadas no racionalismo positivista, propusemos alternativas de avaliação com vistas a ressignificar tais práticas, pensandoas segundo os letramentos críticos (COPE \& KALANTZIS, 2000; MONTE MÓR, 2013; DUBOC, 2007; ROCHA \& MACIEL, 2013; LOPES \&

TAVARES, 2013). Espera-se que essa discussão possa gerar reflexões sobre a formação do professor de línguas, produção e criação de alternativas para práticas avaliativas à luz do letramento crítico.

Palavras-chave: Avaliação; (Multi)letramentos críticos; Ensino de línguas

\section{FABio NAscimento SANDES}

Mestrando do PPGCEL - Programa de Pósgraduação em Letras: Cultura, Educação e Linguagens da UESB-Universidade Estadual do Sudoeste da Bahia; Vitória da Conquista; Bahia; Brasil fnsandes@gmail.com

Abstract: This study introduces theories about assessing in English language, whose aim was the assessment practices from a public school in a small city of Bahia. Towards the perception of recurring conservative practices based upon a positivist rationalism, we proposed assessment alternatives in order to reframe such practices, in compliance with the critical literacies studies (COPE \& KALANTZIS, 2000; MONTE MÓR, 2013; DUBOC, 2007; ROCHA \& MACIEL, 2013; LOPES \& TAVARES, 2013). We hope that the discussion herein presented can bring about reflective issues concerning language teaching service, alternative production and creation for assessment praxis based upon critical literacy.

Key-words: Assessment; Critical (Multi)literacies; Language teaching 



\section{Considerações Iniciais}

O texto a seguir passou a ser delineado ao final da disciplina Introdução à Linguística Aplicada, em abril de 2012, ainda na Graduação em Letras Modernas da UESB, Vitória da Conquista - BA, quando a temática da avaliação ganhou novos contornos naquela instituição em função das teorias de (Multi)letramentos. Para além da disciplina, os debates empreendidos no Grupo de Pesquisa em Linguagem e Educação GPLEd (UESB - CNPq), bem como as reflexões obtidas após o $\mathrm{V}$ encontro do Projeto Nacional "Novos Letramentos, Multiletramentos e Ensino de Línguas" no prédio de Letras da FFLCH - USP em fevereiro de 2014, lançaram as bases para essa discussão.

Os esboços gerados no Mestrado e os insights promovidos nos encontros apontaram para as múltiplas possibilidades de diálogo que os estudos do letramento, bem como os estudos entre cultura escrita e cognição, têm com a temática com que nos propusemos a dialogar: a tradição normativo-prescritiva da avaliação no contexto do Ensino Fundamental e Médio de uma escola pública em uma cidade interiorana da Bahia.

Após o acompanhamento de eventos e práticas de letramento daquele contexto, chegamos à conclusão de que seria necessária uma intervenção de cunho reformista, baseada na concepção de função social que tem o professor, isto é, de intelectual transformador, de pesquisador-em-ação (MOREIRA \& SILVA, 1995, p. 11), com vistas a dissipar a estagnação e a ausência de acontecimentos relevantes para a formação educacional dos alunos.

Segundo Street (2000, p. 70), a naturalização é sempre um momento perigoso em qualquer empreendimento intelectual e nos parece que as práticas testemunhadas naquele contexto são costumeiras, fixas, regulares e, por isso, já naturalizadas. Pressupõe- 
se que o grupo de professores em exercício naquela comunidade carece de algumas necessidades de formação não contempladas pelo currículo de suas licenciaturas, sobretudo no que diz respeito aos letramentos enquanto práticas sociais, à avaliação como lugar de interseção entre ensino e aprendizagem e à formação crítica dos alunos (ROCHA e MACIEL, 2013, p. 7).

Assim, partimos de construtos sociais locais que ratificam posicionamentos a respeito de "que lado da fronteira se está localizado na produção do conhecimento" (MOITA LOPES, 2006) em práxis dentro e fora da sala de aula, refletindo a respeito de provas aplicadas no contexto local para então teorizar e propor uma alternativa, no intuito de tornar o pedagógico mais político e o político mais pedagógico (MOREIRA \& SILVA 1995, p.14), isto é, incentivando os alunos a atuarem como agentes críticos, questionando como o conhecimento pode ser produzido e distribuído.

Nesse sentido, Monte Mór (2013) assinala que o processo de globalização reforça hegemonias que funcionam comoum modo sistemático e institucionalizado de educar, persuadir e representar as classes subordinadas em certas práticas culturais dentro do contexto das normas capitalistas. Desse modo, a avaliação constitui um exemplo nítido dessa relação hierárquica de padronização e normatividade. Ainda nessa perspectiva de poder hegemônico, depreende-se que os sujeitos tornam-se receptores relegados à construção de sentidos de outros, ao invés de serem estimulados as suas próprias construções de sentido, isto é, de se tornarem sujeitos produtores de seus próprios textos (ARTZ 2003 apud MONTE MÓR 2013, p.47).

Diante do que foi exposto, cumpre-nos enfatizar que a avaliação, enquanto área de estudo e pesquisa, ainda é uma disciplina marginal na academia no Brasil (MICCOLI, 2006, p.7) e, pelo fato de nossos cursos de 
graduação e pós-graduação ainda não dedicarem um espaço em suas grades curriculares para discussões sobre o tema, a avaliação passa a ser relegada a segundo plano nos cursos de formação, o que acentua a necessidade de multiletrar os licenciandos nessa matéria, tendo em vista que as licenciaturas em letras exercem a função de preparar sujeitos para serem futuros profissionais de outras instituições.

\section{Cognição, Tecnologias e Letramentos: algumas reflexões}

Em seu texto "Diversidade linguística e pensamento", Soares (2001) apresenta reflexões que permitem compreender os processos cognitivos como resultantes de uma complexa articulação entre sujeito, cultura, linguagem e sociedade. A autora dá enfoque ao caráter dialógico da linguagem proposto por Bakhtin. Segundo ela, o dialogismo é condição sine qua non de sustentabilidade das relações entre linguagem, cultura, pensamento e cognição.

Snyder e Lankshear (2000) ressaltam que o momento histórico atual leva a pensar em letramento e tecnologia de maneiras diferentes. Como atestam os autores, "o que letramento significa num dado momento e em dada época, está diretamente relacionado com as tecnologias disponíveis naquele local e naquele momento" (SNYDER \& LANKSHEAR, 2000, p. 25 apud ELUF, 2010, p. 22).

Parafraseando a discussão de Monte Mór no V Encontro do Projeto Nacional Novos Letramentos e Ensino de Línguas - USP, 2014 - uma terceira geração de Letramentos seria aquela que "abraça a educação, as tecnologias, os novos, os multiletramentos e o letramento crítico". No mesmo encontro, Menezes de Souza afirma que, nesse contexto de tecnologias e educação "não é só 
lembrar o que, mas quem está usando e onde" (MONTE MÓR \& MENEZES DE SOUZA, 2014).

Dentro dessa lógica, quando há “mudança nas tecnologias e nos textos contemporâneos [deve] haver também mudança na maneira como a escola aborda os letramentos requeridos por essas mudanças" (ROJO, 2012, p. 99). Nesse sentido, na estrutura social, tais transformações envolvem a questão da educação "e de novas possibilidades de se imaginar letramento" (ROJO, 2012, p. 99).

Diante das novas tendências, Rojo (2012, p.13) traz para o centro o conceito de multiletramentos, desenvolvido inicialmente pelos pioneiros pesquisadores do New London Group (NLG), em 1996, o qual aponta para dois tipos específicos e importantes de multiplicidade presentes em nossas sociedades, principalmente urbanas, na contemporaneidade: a multiplicidade cultural das populações e a multiplicidade semiótica de constituição dos textos por meio dos quais ela se informa e se comunica.

Outra perspectiva para o estudo dos multiletramentos é apresentada por Lankshear \& Knobel (2003), na qual ressaltam que multiletramentos são aqueles que tem como objeto a relação entre a educação e linguagens digitais, estabelecendo novos parâmetros sobre a construção do conhecimento (ELUF, 2010, p. 20). Nesse mesmo viés, Rojo (2012) faz uma releitura dos pressupostos de Canclini (2008[1989]) ao dizer que "a produção cultural atual se caracteriza por um processo de desterritorialização, de descoleção e de hibridação que permite que cada pessoa possa fazer 'sua própria coleção', sobretudo a partir das novas tecnologias" (ROJO, 2012, p. 16). Para Canclini, "essa apropriação múltipla de patrimônios culturais abre possibilidades originais de experimentação e de comunicação, com usos democratizadores" (CANCLINI, 2008 [1989], p. 308 apud ROJO, 2012, p. 16). Nessa esteira, trata-se de 
descolecionar os "monumentos" patrimoniais escolares, pela introdução de novos e outros gêneros de discurso ditos por Canclini “impuros" -, de outras e novas mídias, tecnologias, línguas, variedades, linguagens (ROJO, 2012, p. 16).

A descoleção dos monumentos escolares, a que se refere o antropólogo argentino, diz respeito a novas alternativas de comunicação, representação e avaliação. Tais formas tornam-se insistentemente necessárias, haja vista a transição do engajamento com o texto impresso para o intensificado conteúdo multimodal na contemporaneidade. Deparamo-nos aqui com outro argumento de acordo com a discussão empreendida. A padronização e a descorporificação de avaliações em massa rompem com a alteridade, com o respeito à subjetividade. Como sugere Rojo (2012),

os estudos são unânimes em apontar que os letramentos são interativos; mais que isso, colaborativos; fraturam e transgridem as relações de poder estabelecidas, em especial as relações de propriedade (das máquinas, das ferramentas, das ideias, dos textos [verbais ou não]); são híbridos, fronteiriços, mestiços (de linguagens, modos, mídias e culturas) (ROJO, 2012, p. 22-23).

Mas afinal que relação a socialização como condição necessária para alterações nas formas de pensamento e o dialogismo, como condição de sustentabilidade das relações entre linguagem, cultura, pensamento e cognição tem com a avaliação? $\mathrm{Na}$ verdade, esses processos demonstram a necessidade de determinar a avaliação escolar não mais como verificação de um resultado ou como instrumento de poder que demarca a assimetria dos participantes no ato educativo, isto é, na concepção do conhecimento privado individual e competitivo (LOPES e TAVARES, 2013), mas na concepção de aprender e conversar juntos, escolhendo e adotando o diálogo, de 
modo a nos engajar mutuamente em uma parceria de aprendizagem. Lopes e Tavares trazem à lembrança os ensinamentos freireanos que aludem ao aprendizado da realidade por meio de uma rede de colaboração, na qual um ajuda o outro a desenvolver-se ao mesmo tempo em que se desenvolvem. Todos aprendem juntos e em colaboração. Ninguém treina ninguém. Ninguém educa o outro (LOPES e TAVARES, 2013).

Por isso frisamos a necessidade de revisão dos paradigmas que aludem à avaliação educacional, pois partimos do pressuposto de que a base do processo educativo deve estar na atividade pessoal do aluno, e, parte integrante do ofício do educador deve estar voltada para promover e moderar essa atividade. No processo de avaliação, o professor deve procurar alternativas e criar um ambiente acolhedor, estimulando parcerias, não individualismos, ser um facilitador, permitindo que seus alunos dirijam seus próprios movimentos.

\section{Do letramento escolar ao letramento crítico}

Concebendo o processo avaliativo como prática de letramento escolar, não poderíamos protelar a discussão sobre a travessia do letramento escolar ao letramento crítico. O letramento escolar, para Signorini (2007, p.324), é um processo complexo e dinâmico de ensinoaprendizagem, constituído de inter-ações entre sujeitos, linguagens e discursos; inter-ações essas mediadas por redes estruturadas e estruturantes de objetos culturais e tecnologias. Segundo a autora:

No processo de alinhamento em sequências de atividades ou programas de ensino, (...) objetos e tecnologias [livro didático, provas e testes oficiais, recortes da mídia impressa ou digital, impressão, xerox, cópia manuscrita, projeção em tela] tanto 
orientam suas ações e as de seus aprendizes, quanto são reorientados por elas nas/pelas interações desencadeadas (SIGNORINI, 2007, p. 324).

Outra curiosidade abordada pela autora diz respeito ao fato desses materiais serem "reconhecidos" ou legitimados pelas redes oficiais de poder e autoridade (SIGNORINI, 2007, p. 326). Para ela, esses materiais são elegíveis como materiais de ensino à disposição do professor, tidos como necessários, quando não obrigatórios, nas redes sociotécnicas que orientam as práticas escolares de letramento (SIGNORINI, 2007, p.326), pois, como atesta Rojo (2012, p. 30), ao invés de se configurar o currículo de acordo com os interesses e talentos dos alunos, o propósito do movimento de avaliação padronizada é definir um núcleo de conhecimento e coagir a escola a ensiná-lo, o que nos remete a uma proposta obsoleta de ensino-aprendizagem.

É preciso, segundo Signorini (2007, p. 330), que a formação regular e continuada crie dispositivos de rompimento ou interrupção das rotinas habituais de "planejamento de atividades" e de "transmissão" de conhecimentos, de modo a favorecer uma experiência comum de construção de conhecimento. A prenda da experiência comum de construção do conhecimento se assemelha àquela reivindicada por Mafalda, no desenho gráfico composto pela imagem da professora na lousa reproduzindo os primeiros rudimentos de leitura da cartilha, a exemplo de sentenças tais como "minha mãe me mima", "minha mãe me ama", à qual Mafalda retruca: "parabéns professora, pelo visto sua mãe é ótima. Agora, por favor, ensine pra gente coisas realmente importantes".

Todavia, há ainda quem acredite, a despeito das críticas ao letramento escolar, nas agências autorizadas de ensino como superestruturas responsáveis, também, pela formação dos sujeitos escolares e, de fato, o são. Bunzen 
(2010, p. 100), por exemplo, sugere que a característica mais importante do letramento talvez seja o caráter variável que deve assumir o conjunto de práticas sócio e histórico-culturais a que damos o nome de "letramento escolar", cuja plasticidade atém-se ao contexto social mais amplo e aos microcontextos.

Logo, o que se espera, dos processos de formação, conforme Signorini (2007, p.332), não é a neutralização da diferença, da tensão e do conflito, mas antes o seu enfrentamento e transformação pela configuração de um espaço de trabalho que promova uma cena ou lugar de enunciação e de experiência comum, em que a controvérsia, a ruptura e o dissenso, conforme aponta Rancière (1995), funcionem como vetores de dinamização e transformação de condições de inteligibilidade e objetivos compartilhados.

Como resultado, comprova-se a relevância da formação inicial e continuada do professor de língua estrangeira, para que haja esse espaço de partilha, discussão, pesquisa e ação a fim de ressignificar teorias e práticas, considerando o conflito, a imprecisão, a contradição e a incompletude como aspectos balizadores das reflexões traçadas acerca das relações humanas e da construção de conhecimentos na sociedade contemporânea (ROCHA e MACIEL, 2013, p. 10). Acreditamos que, nesse espaço, surgem as bases para o letramentos crítico.

Como propõem Rocha e Maciel, mediados pelas novas mídias ou não, o letramento crítico, visto como um exercício de deslocamento e ruptura, passa a ser crucial para a participação democrática, como modo de resistência a discursos e forças hegemônicas (ROCHA e MACIEL, 2013, p.20). Nesse debate, depreende-se que ser crítico é ser "capaz de atravessar os limites do texto em si para o universo concreto dos outros textos, das outras linguagens, capazes de criar quadros mais complexos de referência" (FARACO e TEZZA, 2001, p.239 apud MONTE MÓR, 2013, p.38). 
A crítica, conforme aponta Monte Mór (2013, p. 47), constitui-se elemento imprescindível para um projeto que prevê investigar o fenômeno da globalização, assim como revisar, ampliar e ajustar currículos, epistemologias, habilidades, capacidades, conceitos de linguagem, de cidadania, a relação escola/sociedade, as relações entre professor-aluno (e suas respectivas identidades), a linguagem em suas modalidades e práticas. Por essas razões, o letramento crítico deve perpassar a avaliação, levando em consideração o caráter variável, criativo e rico das práticas sócio e histórico-culturais oriundas dos alunos envolvidos no processo.

\section{Metodologia}

A metodologia aqui descrita filia-se aos estudos da etnografia escolar. Como constata Geertz (1978, p. 4) "segundo a opinião dos livros-textos, praticar a etnografia é estabelecer relações, selecionar informantes, transcrever textos, levantar genealogias, mapear campos, manter um diário". Mas não são essas coisas, segundo o antropólogo americano, que definem o empreendimento. Para ele, o que o define é o tipo de esforço intelectual que ele representa: um risco elaborado para uma "descrição densa" (GEERTZ, 1978, p. 4).

Nesse esforço em elaborar uma descrição densa, nos baseamos no que Lankshear \& Knobel (2013) denominam i) "let's see" research; ii) "try on" research iii) "educationally applicable" research para desenvolver o estudo. Como educadores interessados em avaliar sob a ótica dos letramentos críticos, temos ciência de que nossa pesquisa deva realizar alguma contribuição direta no que se refere à valorização do ensino e aprendizagem no interior de configurações formais de educação (LANKSHEAR \& KNOBEL, 2013, p. 9). 
Portanto, entendemos que fazer etnografia não é descrever o que aconteceu ou não, é demonstrar em que consiste um tipo de interpretação antropológica: traçar a curva de um discurso social; fixá-lo numa forma inspecionável (GEERTZ, 1978, p. 13). Nessa perspectiva, a cultura escolar analisada é um contexto, algo dentro do qual os dados podem ser descritos de forma inteligível isto é, descritos com densidade.

Desse modo, a coleta de dados ocorreu através da inserção dos pesquisadores no contexto de uma escola pública de Ituaçú - Bahia. A prática pedagógica desenvolvida na escola ocorreu entre os meses de Agosto e Dezembro de 2013. Os sujeitos do estudo foram os alunos da escola pública, os professores regentes e em préserviço nos ensinos fundamental e médio. A observação participante, bem como a intervenção pedagógica fizeram parte de um projeto maior, pertencente à Plataforma Paulo Freire, a fim de sistematizar a apresentação da complexidade da avaliação como prática recorrente na aprendizagem de língua estrangeira.

A disciplina foi ministrada na turma de Letras - Prolin, com carga horária de 405 horas e teve como principal objetivo a orientação dos discentes do curso de Letras Inglês, da UNEB Campus VI Caetité, polo no Município de Ituaçu, durante as três modalidades do Estágio Curricular: i) observação; ii) co-participação; e iii) regência, no segundo semestre letivo do ano de 2013.

Em sala de aula, no Campus VI Caetité da UNEB (polo de Ituaçú), procurou-se articular a dimensão da avaliação segundo à Pedagogia dos Multiletramentos e a prática de sala de aula em um processo integralizador capaz de empreender discussões teóricas e práticas na universidade com o objetivo de gerar reflexões e considerações a respeito da avaliação da aprendizagem no estágio supervisionado. Esse percurso subjaz a etapa "let's see" research, a qual tem como principal objetivo um entendimento em profundidade que 
aluda a uma nova prática social e aos letramentos associados ou mobilizados dentro dessa prática (LANKSHEAR \& KNOBEL, 2013, p. 9).

Foram definidos critérios para a elaboração das sequências didáticas, dos planos de aula, do uso do Livro Didático, da construção de práticas pedagógicas lúdicas, sobretudo da formulação de avaliações mais flexíveis, consoante aos pressupostos da Pedagogia de Multiletramentos e letramentos críticos. Nessa etapa, aplicamos a "try on" research, a qual estimula a experimentação de conceitos, teorias e metodologias, incluindo mash-ups inovadores de teorias e métodos, juntamente com o desenvolvimento de novas técnicas e modificações de técnicas existentes de coleta e análise de dados a fim de explorar e entender práticas de letramento cambiáveis e emergentes (LANKSHEAR \& KNOBEL, 2013, p. 9).

No tocante à segunda modalidade do Estágio Curricular, a co-participação, partiu-se de alguns modelos de sequências didáticas para que os graduandos pudessem dar início a reflexões e construções de práticas pedagógicas desenvolvidas para a regência, a qual ocorreu durante o período de 07 de outubro de 2013 até 21 de novembro de 2013. Percebe-se aqui a coerência dessa etapa com a "educationally applicable" research, principalmente no que tange à busca por invenções potencialmente aplicadas para melhor entender ou possibilitar o aprendizado nas escolas e/ou em outros espaços formais de aprendizado.

\section{Práxis em foco: análise de provas elaboradas pelos professores-regentes de Língua Inglesa (LI) de Ituaçú - BA}

Procuramos nos ocupar da formação inicial e continuada de professores de línguas da comunidade 
local que lidam com os macro e microcontextos, para que passassem a desenvolver, em seus contextos educacionais, práticas avaliativas relevantes. Como afirmam Menezes e Sade (2006, p. 53), a avaliação, a depender da elaboração e aplicação, pode causar efeitos devastadores nos alunos, desencorajando-os. Conforme indicam as autoras (2006), os instrumentos de avaliação nem sempre conseguem captar de forma justa o desenvolvimento desse processo (MENEZES e SADE, 2006, p. 52).

Menezes e Sade (2006, p. 48-49) chamam a atenção para a importância do conhecimento prévio na trajetória educacional, por permitir um conhecimento não apenas do conteúdo, mas também de como o processo avaliativo ocorrerá. As autoras referem-se a Kress (1989) para tratarem da socialização na escola, a qual nada mais é do que a imposição ao indivíduo do esquema que o condicionará a atuar e significar o ato social de estudar. Segundo as autoras (2006), alunos já habituados com esse esquema possuem melhores chances de sucesso, logo o professor de línguas, conforme elas apontam, não deve negligenciar o fato de que os diferentes backgrounds de seus alunos certamente influenciarão suas atuações.

Em contextos de avaliação, o conhecimento prévio possui um papel fundamental, sobretudo no que concerne à retenção de uma informação nova, tanto na quantidade quanto na qualidade do que será retido (MENEZES e SADE, 2006, p. 49). A divergência ocorre quando nos deparamos com um evento conflitante, a exemplo da fig. 1, a qual diz respeito ao conteúdo que será requisitado posteriormente pelo professor através da avaliação. Esse conteúdo incoerente, por sua vez, servirá de base para os estágios futuros, acarretando uma série de outros fenômenos. 


\section{(Nust-dener, prescison)}

1 Un scheal murt trave woter of studenty drink.

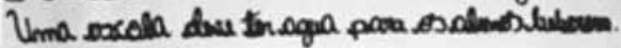

2. We mut cause in livers of school.

cos dowemes trazer es liveres parra a escosta

3. I must respest in teatcher.

Eu deworespeitan o profennor

4- We must have a uniform.

cos devermos ten arm unizerme.

5- We must have in exciose.

scos devemes trazer os sencicicos.

Fig. 1: explanação do verbo modal must

No interior dessa lógica, a ação professoral, repleta de contradições, provoca desdobramentos sérios na organização do pensamento do alunado, uma vez que os conteúdos subsequentes ficam comprometidos em decorrência dos antecedentes, haja vista o desacordo entre os mesmos, afetando, assim, a qualidade e a quantidade do que será retido, bem como a aprendizagem como um todo.

A apresentação da fig. 1 evidencia uma dissonância não só entre a avaliação anunciada e a efetivamente aplicada, mas também entre a apresentação do conteúdo e o que será cobrado a posteriori. Os exercícios abaixo, extraídos de provas elaboradas por professores da referida comunidade, nos remetem a uma concepção de avaliação psicométrica, provida de questões descontextualizadas, fragmentárias e reducionistas, com ênfase em conteúdos objetivos, estáveis e memorizáveis, como se pode evidenciar nas fig. 3 e 4 , além de outras questões que testam a língua e não propriamente o seu uso. 
3. Escreva em português o nome dos seguintes objetos.

a) Dog

b) Cat

c) Lion

d) Mouse

e) Elephant

f) Tiger

g) Ounce

h) Camel

Fig. 2: exercício avaliativo de vocabulário referente aos animais

4. Quantas horas săo?

$13: 30$

$02: 45$

18:00

Fig. 3: exercício avaliativo de vocabulário referente às horas.

Segundo Duboc (2007, p. 267), a avaliação psicométrica a que nos referimos, é fruto do modelo positivista de educação do século XIX, cuja origem encontra-se vinculada ao emergente cientificismo daquela época, com ênfase à experimentação e observação de fatos de forma lógica, racional e concreta. Essa concepção de avaliação, segundo Duboc (2007), pautada em conteúdos e formas que privilegiam a objetividade e a estabilidade, advém da própria concepção de conhecimento que perpassou todo o século XX. Trata-se, como indica a autora (2007), de uma concepção fundamentada pelo racionalismo cartesiano e pautada na ênfase do real e da verdade sobre as coisas, em que se prioriza o conhecimento científico, objetivo, estável, portanto, facilmente transmitido e medido.

Tomando como embasamento aspectos apontados por Baxter (1997) no que se refere ao conteúdo que se deseja avaliar no processo de ensino e aprendizagem de uma língua, Duboc (2007) revela que, dentre os inúmeros aspectos que poderiam ser avaliados, os professores 
priorizam aqueles considerados fáceis de serem ensinados. A autora menciona a ênfase à avaliação da gramática, com significados objetivos e estanques e, consequentemente, de fácil correção, conforme evidenciam as fig. 4 e 5, extraídos de outra prova:
4- Altere as formas abaixo em formas negativas e interrogativas. (1,0) N I
a) He saw an accident this morning.
b) They came to Rio in 1997 . $\mathrm{N}$
c) She went home yesterday. N I
d) He were at school yesterday. N
5. Coloque as frases nas formas negativas e interrogativas. Observando os verbos modais can e could.

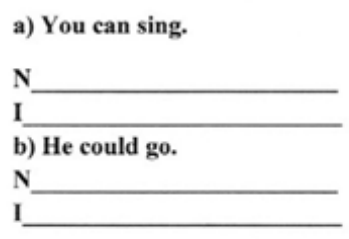
c) She can speak English.

Fig. 5: exercício avaliativo referente aos verbos modais can e could.

Os exercícios acima ganhariam outro status, se pensados sob a perspectiva dos letramentos críticos, uma vez que tal pedagogia põe em perspectiva ensinar os alunos a negociarem os sentidos da linguagem, outrora fixados, incluindo a mobilidade de lidar com as variações linguísticas regionais, étnicas ou de classe (COPE e KALANTZIS, 2000).

A fig. 3 representa outro momento oportuno para refletir sobre como avaliar segundo a ótica dos letramentos críticos. Para além de meramente focalizar o vocabulário respeitante às horas em sua forma escrita, o exercício o faz de modo desconexo. Um modo mais proveitoso de trabalhar as horas, consoante aos pressupostos teóricos dos letramentos, seria, conforme sugerem Viens e Kallenbach (2004), demarcar os quatro fusos horários brasileiros num mapa do Brasil em branco. Após desenhar os fusos, 
os alunos deveriam escrever alguns estados no mapa, podendo consultar um mapa de referência para completar o restante. Os alunos deveriam então, mostrar no mapa que horas são em cada fuso horário no momento em que levantam, almoçam, jantam e dormem.

Esse trabalho potencializaria uma discussão mais frutífera acerca do tema, uma vez que cederia espaço à viabilização da crítica, em cujo processo manifestam-se a subjetividade e a possibilidade de (re)criação de sentidos sobre o texto (DUBOC, 2007). Como observa Duboc (2007, p. 274), a inclusão de conteúdos dessa natureza pode significar um exercício bastante "laborioso e desafiador" para o professor, já que não estamos habituados a considerar tais aspectos em momentos avaliativos formais. Contudo, a autora acredita que o trabalho pedagógico dessa natureza mostra-se amplamente enriquecedor para a formação crítica dos alunos.

Por isso a necessidade de ampliação do enfoque na avaliação sob o prisma dos letramentos críticos na formação de professores, a fim de viabilizar uma confluência entre discurso e prática. Essa foi nossa intenção quando selecionamos o título barking up the wrong tree: refletir acerca dos efeitos da avaliação dogmática e normativa, subordinada à lógica do conservadorismo, no intuito de fazer converter o esforço dispendioso empreendido nesse tipo de avaliação em um processo alternativo mais crítico, cidadão, justo e democrático.

Parece oportuno, nesse momento, destacar que não tivemos a pretensão de emitir um juízo de valor no tocante à avaliação promovida pelos professores em exercício da referida comunidade, mas sim retratar práticas avaliativas dogmáticas e reducionistas em um município onde letramento crítico e outros componentes midiáticos ainda não haviam sido experienciados em práticas de aprendizagem e ensino de LI. 
Cumpre enunciar que essa lacuna na formação educacional dos sujeitos-participantes da pesquisa é consequência de uma sociedade cuja maior parte da população, embora seja multisemiotizada e plural (ROCHA e MACIEL, 2013, p. 22), tem acesso estritamente à educação hegemônica, vista como "uma forma imposta de ignorância", que aliena e coíbe uma ação mais ampla e criticamente orientada (ROCHA e MACIEL, 2013, p. 22).

Em vista disso, chegamos à conclusão de que o padrão de avaliação em foco é reflexo de um sistema normativo que incita a competição ao invés de colaboração, que dispõe de estratégias utilitaristas, ao invés da distribuição do conhecimento, o que nos remete ao problema da exclusão no ensino em face dos valores globalizantes.

\section{Considerações Finais}

Nesse texto, debruçamo-nos sobre uma questão central: como formar o professor de língua estrangeira de modo a transgredir sua prática avaliativa em sala de aula, a fim de torná-los capazes de atuar como agentes críticos em seus contextos sociais. Nosso intuito foi potencializar uma discussão mais crítica acerca do tema, dando especial enfoque às diferenças linguísticas e às suas interferências nos processos cognitivos e de socialização em processos de avaliação, na tentativa de estabelecer novos fundamentos para o tema.

Esperamos que o convite para pensar a prática avaliativa à luz do letramento crítico abra novas possibilidades reais de experimentação e de comunicação, com usos democratizadores da avaliação, de modo que possa abandonar o caráter de mera verificação de um resultado ou instrumento de poder, o qual demarca a assimetria dos participantes no ato educativo e estimule o aprender e compartilhar, escolhendo e adotando o diálogo 
numa busca incessante por um engajamento mútuo e uma parceria de aprendizagem.

Embora tenhamos plena ciência da dificuldade em produzir conhecimento acerca do tema, tendo em vista o enquadramento da avaliação, enquanto área de estudo e pesquisa, como uma disciplina ainda marginal na academia (vide Introdução) e, pelo fato de muitos cursos de graduação e pós-graduação ainda não dedicarem um espaço em suas grades curriculares para discussões a tal respeito, insistimos em tratar o assunto, sobretudo porque, como disse o sociólogo De Sousa Santos (2010, p. 96) parafraseando o filósofo francês Sartre: "antes de concretizada, uma ideia apresenta uma estranha semelhança com a utopia. Nos tempos que correm, o importante é não reduzir a realidade apenas ao que existe".

Certamente, as apostas e os avanços originados a partir desse artigo proveram um significativo amadurecimento teórico e prático em nossa formação. Que esta oportunidade para repensar, problematizar e contrapor as questões da avaliação conservadora convidem os interessados nessa área a ressignificar sentidos e práticas, de modo a enfrentar os desafios que nos são postulados como profissionais da linguística aplicada. Um desafio que certamente não se esgota na teorização e que, obviamente, instiga e provoca a todos aqueles que se interessam pelas questões avaliativas e dos letramentos. 


\section{Referências}

BROWN, H. D. Principles of Language Learning and

Teaching. 3. Ed. Englewood Cliffs: Prentice Hall Inc., 1994.

BUNZEN, C. Os significados do letramento escolar como uma prática sociocultural. In: VÓVIO, C; SITO, L; DE GRANDE, P. Letramentos. rupturas, deslocamentos e repercussões de pesquisa em Linguística Aplicada. Campinas: Mercado de Letras, 2010.

CELANI, M. A. A. A Relevância da Linguística Aplicada na Formulação de uma Política Educacional Brasileira. In: BÁRBARA, L.; RAMOS, R.G.C. (Org.). Reflexão e ações no ensino-aprendizagem de Línguas. Campinas: Mercado das Letras, 2003.

COPE , B. \& KALANTZIS, M. (eds.). Multiliteracies. literacy learning and the design of social futures. London: Routledge, 2000 .

DE SOUSA SANTOS, B. Descolonizar el saber, reinventar el poder. Ediciones Trilce, 2010.

DUBOC, A. P. M. A avaliação da aprendizagem de língua inglesa segundo as novas teorias de letramento. Fragmentos, número 33, p.263277. Florianópolis/ jul - dez/ 2007.

ELUF, C. A. Nova interface pedagógica: linguística de corpust multiletramentos na formação do professor de língua inglesa. Tese de doutoramento. Universidade de São Paulo, 2010, mimeo.

GNERRE, M. Linguagem, escrita e poder. 4. ed. São Paulo: Martins Fontes, 1998.

GEERTZ, C. Uma Descrição Densa: Por uma Teoria Interpretativa da Cultura. In: GEERTZ, C. $A$ interpretação das culturas. Rio de Janeiro/RJ: Zahar editores, 1978. 
LARSEN-FREEMAN, D. Chaos/complexity science and second language acquisition. Applied linguistics, 18, n. 2, 1997.

LANKSHEAR, C.; SNYDER, I. with GREEN, B. Teachers and Techno-Literacy: Managing Literacy, Technology and Learning in Schools. Malaysia: SRM Production Services, 2000.

LANKSHEAR, C.; KNOBEL, M. New Literacies: Changing Knowledge and Classroom Learning. Buckingham, UK: Open University Press, 2003.

. A new literacies reader: educational perspectives /

edited by Colin Lankshear, Michele Knobel. New York: Peter Lang, 2013.

LOPES, M. C. L. P; TAVARES, R. R. Globalização, Interação e Letramento crítico: formação continuada de professores em contexto digital no Brasil. In: Roseanne Rocha Tavares; Diana Brydon. (Org.). Letramentos Transnacionais. mobilizando conhecimento entre Brasil/Canadá. 1 ed. Maceió: Edufal, 2013, v. 1, p. 65-75.

MENEZES, V.; SADE, L. A. Avaliação, Cognição e Poder. In: Revista Brasileira de Linguística Aplicada, v.6, n.2. Belo Horizonte: Faculdade de Letras das UFMG, 2006.

MENEZES DE SOUZA, L. M. V Encontro do Projeto Nacional Novos Letramentos, Multiletramentos e Ensino de Línguas, USP, 2014.

MICCOLI, L. S. Revista Brasileira de Linguística Aplicada, v.6, n.2. Belo Horizonte: MG: Faculdade de Letras das UFMG, 2006.

MOITA LOPES, L. P. Por uma linguística Indisciplinar. São Paulo: Parábola Editorial, 2006. 
MONTE MÓR, W. Sobre homogeneidade e heterogeneidade no ensino de línguas e as influências dos conceitos 'estadonação’ e 'globalização'. In: Roseanne Rocha Tavares; Diana Brydon. (Org.). Letramentos Transnacionais: mobilizando conhecimento entre Brasil/Canadá. 1 ed. Maceió: Edufal, 2013, v. 1, p. 39-50.

. Crítica e letramentos críticos: reflexões preliminares. In: ROCHA, C. H.; MACIEL, R. F. (Orgs.) Língua estrangeira e formação cidadã: por entre discursos e práticas. Coleção Novas perspectivas em linguística Aplicada. Vol. 33. Campinas, SP: Pontes Editores, 2013.

. V Encontro do Projeto Nacional Novos Letramentos, Multiletramentos e Ensino de Línguas, USP, 2014.

MOREIRA, A. F.; SILVA, T. T. Territórios contestados: o currículo e os novos mapas políticos e culturais. Petrópolis: Vozes, 1995.

ROCHA, C. H.; MACIEL, R. F. (Orgs.) Língua estrangeira e formação cidadã: por entre discursos e práticas. Coleção: Novas perspectivas em linguística Aplicada. Vol. 33. Campinas: Pontes Editores, 2013. . Língua estrangeira, formação cidadã e tecnologia: ensino e pesquisa como participação democrática. ROCHA, C. H.; MACIEL, R. F. (Orgs.) Língua estrangeira e formação cidadã: por entre discursos e práticas. Coleção: Novas perspectivas em linguística Aplicada. Vol. 33. Campinas: Pontes Editores, 2013.

ROJO, R.; MOURA, E. (Orgs.). Multiletramentos na escola. São Paulo: Parábola Editorial, 2012.

SIGNORINI, I. Letramento escolar e formação do professor de língua portuguesa. In: KLEIMAN, A. B., CAVALCANTI, M. C. (orgs.) Linguística Aplicada: suas faces e interfaces. Campinas: Mercado de Letras, 2007. 
SOARES, M. Diversidade lingüística e pensamento. MORTIMER, E.F. e SMOLKA, A.L.B.

Linguagem, Cultura e Cognição: reflexões para o ensino e a sala de aula. Belo Horizonte: Autêntica, 2001.

STREET, B. Eventos e Práticas de Letramento. In: MAGALHÃES, I. Discursos e práticas de letramento: uma pesquisa etnográfica e formação de professores. Izabel Magalhães (org.). Campinas, SP: Mercado de Letras, 2012.

VIENS, J.; \& KALLENBACH, S. Multiple intelligences and adult literacy: A sourcebook for practitioners. Teachers College Press, 2004.

Recebido em 27/02/2014 Aceito para publicação em 30/07/2014 